\title{
Baicalin protects the myocardium from reperfusion-induced damage in isolated rat hearts via the antioxidant and paracrine effect
}

\author{
FENG KONG $^{1 *}$, YUN LUAN $^{1 *}$, ZHAO-HUA ZHANG $^{2}$, GUANG-HUI CHENG $^{1}$, TONG-GANG QI ${ }^{1}$ and CHAO SUN ${ }^{1}$ \\ ${ }^{1}$ Central Research Laboratory; ${ }^{2}$ Department of Pediatrics, The Second Hospital of Shandong University, \\ Jinan, Shandong 250033, P.R. China
}

Received July 4, 2013; Accepted October 24, 2013

DOI: $10.3892 /$ etm.2013.1369

\begin{abstract}
The aim of the present study was to investigate the protective effect of baicalin (BA) against ischemia-reperfusion (I/R) injury in isolated rat hearts. Sprague-Dawley rat hearts were rapidly removed, mounted on a Langendorff apparatus and subjected to $30 \mathrm{~min}$ ischemia followed by $30 \mathrm{~min}$ reperfusion with Krebs-Henseleit (K-H) solution at $37^{\circ} \mathrm{C}$ to establish the isolated I/R injury model. All animals $(n=50)$ were randomly divided into five groups ( $\mathrm{n}=10$ in each): I, normal control; II, I/R; III, I/R plus $20 \mathrm{mg} / \mathrm{kg} \mathrm{BA;} \mathrm{IV,} \mathrm{I/R} \mathrm{plus} 40 \mathrm{mg} / \mathrm{kg}$ $\mathrm{BA}$; and $\mathrm{V}, \mathrm{I} / \mathrm{R}$ plus $80 \mathrm{mg} / \mathrm{kg}$ BA. The degree of heart injury caused by the I/R was assessed by evaluating left ventricular function and by detecting the levels of lactate dehydrogenase $(\mathrm{LDH})$ and creatine kinase $(\mathrm{CK})$ in the coronary effluent and the myocardial superoxide dismutase (SOD) and malondialdehyde (MDA) levels in the isolated rat hearts. Myocardial infarct size and vascular density were assessed using histology and immunohistochemistry. The apoptotic cardiomyocytes were determined using flow cytometry (FCM). Compared with group II, the BA groups demonstrated improved left ventricular function, reduced CK and LDH release in the coronary effluent and increased SOD and MDA activity $(\mathrm{P}<0.05)$. Furthermore, histology and immunohistochemistry results showed that the infarct size was reduced and vessel density was augmented in the BA groups $(\mathrm{P}<0.01)$ compared with group II. The FCM results indicated that apoptosis was significantly lower in the BA groups than in group II $(\mathrm{P}<0.05)$ and that the protective effect was dose-dependent. In conclusion, these results demonstrated that BA exerts a dose-dependent protective effect on $\mathrm{I} / \mathrm{R}$ injury in isolated rat hearts, the mechanisms of which may
\end{abstract}

Correspondence to: Mrs Yun Luan, Central Research Laboratory, The Second Hospital of Shandong University, 247 Beiyuan Dajie, Jinan, Shandong 250033, P.R. China

E-mail: y_luan@aliyun.com

${ }^{*}$ Contributed equally

Key words: baicalin, ischemia-reperfusion, FCM, apoptosis, heart be associated with antioxidant and anti-apoptosis properties. To the best of our knowledge, this study is the first evaluation of the efficacy of BA in isolated rat hearts using histology and immunohistochemistry, providing a foundation for the use of $\mathrm{BA}$ in the treatment of acute myocardial infarction.

\section{Introduction}

Ischemia-reperfusion (I/R) injury remains the leading cause of morbidity and mortality in all developed countries and is a large economic burden in the treatment and care of patients (1). $\mathrm{I} / \mathrm{R}$ injury of the heart is the underlying pathophysiology of acute myocardial infarction (AMI), which is one of the most common causes of mortality globally (2). Following cell $\mathrm{I} / \mathrm{R}$, apoptosis is one of the major pathways that leads to the process of cell death. Numerous studies have indicated that cell apoptosis is associated with a variety of damaging stimuli, particularly continuous $\mathrm{I} / \mathrm{R}$, in vitro and in the intact heart in vivo (3-7). Thus, protection against $\mathrm{I} / \mathrm{R}$ injury in the heart is of marked importance.

Chinese herbal medicine has been used to treat diseases for thousands of years and it has recently attracted the attention of practitioners of Western medicine. However, the effective ingredients in the majority of these medications have not been identified. Baicalin (BA; $\mathrm{C}_{21} \mathrm{H}_{18} \mathrm{O}_{11}$, 7-glucuronic acid, 5,6-dihydroxy-flacone), a Chinese traditional medicinal herb, possesses antioxidant properties and free radical scavenging activity (8-12). Studies have demonstrated that BA can suppress the proliferation of vascular smooth muscle cells (9) and exert cardioprotective effects against hypoxia/reoxygenation injury (12-16). However, the cardioprotective properties have not been confirmed and the mechanism has not been fully characterized. In addition, there has been no clear histological or immunohistochemical evidence showing the cardioprotective effect of BA to date. Therefore, further studies investigating the mechanisms of protection are required.

The Langendorff mouse heart model is widely used in studies of myocardial function and responses to injury (17). In the present study, rat hearts were isolated and perfused using the Langendorff technique to establish a high-throughput and potentially reliable I/R model. 
The aim of the present study was to evaluate the efficacy of $\mathrm{BA}$ in isolated rat hearts using hemodynamic, histological and immunohistochemical observations.

\section{Materials and methods}

Animals. Male Sprague-Dawley rats, weighing 250-300 g, were purchased from the Experimental Animal Center of Shandong University (Jinan, China). The rats were housed within the animal care facility at a constant room temperature with a 12:12-h light-dark cycle and were provided with standard rat chow and water ad libitum for at least 3 days prior to the initiation of the experiments. All animals received humane care in compliance with the Guide for the Care and Use of Laboratory Animals published by the US National Institute of Health (NIH publication no. 85-23; revised 1996). The study was approved by the Ethics Committee of the Shandong University (Jinan, China).

Langendorff isolated perfused heart preparation. Rats were anesthetized with pentobarbital sodium (50 $\mathrm{mg} / \mathrm{kg}$ ip) and administered with the anticoagulant, heparin sodium (10,000 USP U/kg ip). Following this, a thoracotomy was performed and the hearts of the rats were rapidly excised into ice-cold arresting solution $(120 \mathrm{mmol} / \mathrm{l} \mathrm{NaCl}$ and $30 \mathrm{mmol} / \mathrm{l}$ $\mathrm{KCl}$ ). The aorta was cannulated on a 20 -gauge stainless steel blunt needle and perfusion was initiated at $70 \mathrm{mmHg}$ on a Langendorff apparatus. A modified Krebs-Henseleit (K-H) perfusion solution was used in all experiments, containing $118 \mathrm{mmol} / 1 \mathrm{NaCl}, 4.7 \mathrm{mmol} / 1 \mathrm{KCl}, 2.5 \mathrm{mmol} / \mathrm{C} \mathrm{CaCl}_{2}, 1.2 \mathrm{mmol} / \mathrm{l}$ $\mathrm{MgSO}_{4}, 1.2 \mathrm{mmol} / 1 \mathrm{KH}_{2} \mathrm{PO}_{4}, 24 \mathrm{mmol} / 1 \mathrm{NaHCO}_{3}, 5.5 \mathrm{mmol} / \mathrm{l}$ glucose, $5.0 \mathrm{mmol} / 1$ sodium pyruvate and $0.5 \mathrm{mmol} / 1 \mathrm{EDTA}$ bubbled with $95 \% \mathrm{O}_{2}-5 \% \mathrm{CO}_{2}$ at $37^{\circ} \mathrm{C}(\mathrm{pH} 7.4)$. Electrodes were placed in the upper left and lower right regions of the heart and a left ventricular catheter with a pressure transducer (TP-400T; Nihon Kohden Corp., Tokyo, Japan) was connected to the Medlab Biosignal Acquisition System (MedLab-U/4C501, Top Instrument Co., Ltd., Hangzhou, China), to record heart rate (HR), left ventricular end-diastolic pressure (LVEDP), left ventricular developed pressure (LVDP), mean coronary flow $(\mathrm{CF})$ and the first derivative of the left ventricular pressure during a cardiac cycle (maximum and minimum LV $\mathrm{dP} / \mathrm{dt}$ ). Heart pacing at 360 beats/min was initiated following 30 min stabilization to normalize HR across the groups. All hemodynamic parameters were continuously recorded on an eight-channel thermal-pen recorder (WT-685G; Nihon Kohden Corp.). Coronary effluent samples were obtained at 5, 15, 25, 35, 45 and $55 \mathrm{~min}$ of perfusion, and stored at $-20^{\circ} \mathrm{C}$ for the measurement of lactate dehydrogenase (LDH) and creatine kinase (CK) activity. At the end of reperfusion, the left ventricular free wall was rapidly excised and stored at $-80^{\circ} \mathrm{C}$ for subsequent determination of the levels of antioxidant enzymes.

Experimental protocols. BA (purity $>95 \%$ ) was purchased from Sigma (St. Louis, MO, USA) and dissolved in saline prior to being added into the perfusion solution. All hearts were perfused with the K-H solution for a total of $120 \mathrm{~min}$ (at $37^{\circ} \mathrm{C}$ ), consisting of a 30 -min preischemic period followed by $30 \mathrm{~min}$ of ischemia and $60 \mathrm{~min}$ of reperfusion. The hearts were randomly divided into five experimental groups. Group I (normal): Hearts $(n=10)$ were perfused for 90 min with $\mathrm{K}-\mathrm{H}$ solution as a normal control for the different experimental groups. Group II (I/R): Following equilibration, hearts $(n=10)$ were subjected to ischemia for $30 \mathrm{~min}$, prior to being reperfused for $60 \mathrm{~min}$ with K-H solution. Groups III, IV and V (I/R plus BA): Hearts ( $\mathrm{n}=10$ each) were perfused similarly to group II, except that the reperfusion solution contained 20,40 and $80 \mathrm{mg} / \mathrm{kg} \mathrm{BA}$, respectively.

Assessment of myocardial damage. Activities of CK and LDH in the coronary effluent were measured by a 722 Visible Spectrophotometer (Shanghai Laipade Science Instruments Co., Ltd, Shanghai, China) using a Sigma assay kit at $340 \mathrm{~nm}$, as described previously (18). Samples of the perfusate and the coronary effluent were collected following 5, 15, 25, 35 and $60 \mathrm{~min}$ of reperfusion and frozen in liquid nitrogen.

The malondialdehyde (MDA) level and superoxide dismutase (SOD) activity in the frozen myocardial tissue were measured using commercial kits (Nanjing Jiancheng Bioengineering Institute, Nanjing, China) with the 722 Visible Spectrophotometer at $532 \mathrm{~nm}$ (19). The cardiac tissue samples were weighed and homogenized (1:10, w/v) in $50 \mathrm{mmol} / \mathrm{l}$ phosphate buffer and maintained in an ice bath. The amount of thiobarbituric acid-reactive substances was estimated as MDA and SOD equivalents per gram of wet myocardial weight.

Evaluation of myocardial infarct size. Following reperfusion and the rapid excision of the heart, the tissues were fixed with $10 \%$ formaldehyde, cut transversely, from apex to base, into six slices and embedded in paraffin. Serial sections $(1 \mathrm{~cm})$ of the embedded tissue were stained with hematoxylin-eosin and Masson's trichrome stain (Baso Biotechnology, Shenzhen, China) and the amount of surviving myocardium was measured using Masson's stain. For each slice, the area at risk and the area of infarction were determined by the sum of the planimetered endocardial and epicardial circumferences of the infarcted area divided by the sum of the total endocardial and epicardial circumferences of the left ventricle, as described previously $(20,21)$.

Analysis of vessel density. The hearts were rapidly harvested and the tissues in the infarcted zone were collected. The tissues were subsequently embedded in optimal cutting temperature compound (Sigma), rapidly frozen in liquid nitrogen and stored at $-80^{\circ} \mathrm{C}$. Having been fixed in acetone for $10 \mathrm{~min}$ at $4^{\circ} \mathrm{C}$, cryostat sections were then cut into $5-\mu \mathrm{m}$ slices and incubated with primary antibodies. Immunohistochemical staining was performed with an antibody against von Willebrand factor (vWF; 1:100; Abcam, Cambridge, UK), in accordance with the manufacturer's instructions. The vascular density was counted blind on 100 sections in the infarcted areas of all animals and then stained with an anti-vWF antibody, using a light microscope at a magnification of $\mathrm{x} 400$. The average of the 10 high-power fields (hpfs) was randomly selected and the vascular density was defined as the number of vessels/hpf in the infarcted area $\left(0.2 \mathrm{~mm}^{2}\right)$. Samples were randomized and two examiners, blind to treatment design, were used for analysis.

Assay of apoptosis. Cardiomyocyte apoptosis was analyzed via flow cytometry (FCM) using a FACSCalibur system with CellQuest acquisition software (BD Pharmingen, Inc., 
Table I. Effect of baicalin on LDH and CK activity in the coronary effluent.

\begin{tabular}{|c|c|c|c|c|c|c|c|c|}
\hline \multirow[b]{2}{*}{ Group } & \multirow[b]{2}{*}{ Parameter } & \multirow[b]{2}{*}{ Preischemia } & \multicolumn{6}{|c|}{ Reperfusion, $\mathrm{U} / \mathrm{ml}$} \\
\hline & & & $5 \mathrm{~min}$ & $15 \mathrm{~min}$ & $25 \mathrm{~min}$ & $35 \mathrm{~min}$ & $45 \min$ & $55 \mathrm{~min}$ \\
\hline \multirow[t]{2}{*}{ II } & CK & $33 \pm 2.6$ & $58 \pm 3.7$ & $60 \pm 4.5$ & $62 \pm 1.7$ & $63 \pm 6.3$ & $65 \pm 4.5$ & $68 \pm 5.8$ \\
\hline & LDH & $2.38 \pm 0.2$ & $10.27 \pm 0.3$ & $10.26 \pm 0.1$ & $9.48 \pm 0.2$ & $9.25 \pm 0.5$ & $9.16 \pm 0.1$ & $8.70 \pm 0.4$ \\
\hline \multirow[t]{2}{*}{ III } & $\mathrm{CK}$ & $32 \pm 3.7$ & $57 \pm 5.1$ & $55 \pm 4.9^{\mathrm{a}}$ & $49 \pm 8.1^{\mathrm{a}}$ & $42 \pm 3.4^{\mathrm{a}}$ & $38 \pm 2.6^{b}$ & $36 \pm 1.4^{\mathrm{b}}$ \\
\hline & LDH & $2.43 \pm 0.6$ & $9.61 \pm 0.7$ & $8.13 \pm 0.4^{\mathrm{a}}$ & $7.25 \pm 0.8^{\mathrm{a}}$ & $6.38 \pm 0.9^{b}$ & $5.10 \pm 0.4^{\mathrm{b}}$ & $4.90 \pm 0.6^{\mathrm{b}}$ \\
\hline \multirow[t]{2}{*}{ IV } & CK & $34 \pm 2.8$ & $56 \pm 3.8$ & $55 \pm 2.6^{\mathrm{a}}$ & $47 \pm 6.3^{\mathrm{a}}$ & $39 \pm 1.8^{\mathrm{bc}}$ & $37 \pm 4.7^{\mathrm{bc}}$ & $35 \pm 2.1^{\mathrm{bc}}$ \\
\hline & LDH & $2.36 \pm 1.7$ & $9.37 \pm 1.3$ & $7.37 \pm 1.3^{\mathrm{a}}$ & $6.28 \pm 1.2^{\mathrm{a}}$ & $5.34 \pm 1.2^{\mathrm{bc}}$ & $4.60 \pm 0.8^{\mathrm{bc}}$ & $3.60 \pm 0.7^{\mathrm{bc}}$ \\
\hline \multirow[t]{2}{*}{$\mathrm{V}$} & CK & $32 \pm 4.2$ & $56 \pm 2.6$ & $52 \pm 2.4^{\mathrm{a}}$ & $45 \pm 1.7^{\mathrm{a}}$ & $36 \pm 4.9^{\mathrm{ac}}$ & $34 \pm 4.7^{\mathrm{bcd}}$ & $33 \pm 4.5^{\text {bd }}$ \\
\hline & LDH & $2.36 \pm 1.7$ & $9.24 \pm 1.3$ & $7.26 \pm 2.0^{\mathrm{a}}$ & $5.80 \pm 3.2^{\mathrm{a}}$ & $4.80 \pm 1.3^{\mathrm{bcd}}$ & $4.20 \pm 0.8^{\mathrm{bd}}$ & $3.40 \pm 1.7^{\mathrm{bd}}$ \\
\hline
\end{tabular}

Data are presented as the mean \pm standard error of the mean $(\mathrm{n}=10) .{ }^{\mathrm{a}} \mathrm{P}<0.05$ and ${ }^{\mathrm{b}} \mathrm{P}<0.01$, vs. group II; ${ }^{\mathrm{c}} \mathrm{P}<0.05$, vs. group III; ${ }^{\mathrm{d}} \mathrm{P}<0.05$, vs. group IV. LDH, lactate dehydrogenase; CK, creatine kinase.

San Diego, CA, USA) (22). Briefly, a single-cell suspension the from minced tissue of the LV free wall was obtained by mechanical grinding, prior to filtration through $40-\mu \mathrm{m}$ nylon mesh filters (Falcon Cell Strainers; BD Biosciences Discovery Labware, Bedford, MA, USA). FCM analysis was performed using an Annexin V-fluorescein isothiocyanate (FITC) kit (Immunotech, Beckman Coulter, Miami, FL, USA) according to the manufacturer's instructions: $500 \mu 1$ $1 \mathrm{X}$ Binding Buffer was mixed with $10 \mu 1$ propidium iodide (PI) and $10 \mu \mathrm{l}$ Annexin-V labeled with FITC solutions. The cells were washed twice with ice-cold phosphate-buffered saline and then incubated for $15 \mathrm{~min}$ in $100 \mu \mathrm{l}$ fresh incubation buffer containing PI and FITC-Annexin-V in the dark at room temperature. Following this, the cells $\left(>1 \times 10^{6} / \mathrm{ml}\right)$ were analyzed as soon as possible (within $1 \mathrm{~h}$ ) using FCM.

Statistical analysis. All data are presented as the mean \pm standard error of the mean. A Student's t-test was used to compare the data between two groups and one-way analysis of variance was used to compare the data from more than two groups, followed by the Scheffe multiple-comparison test. Statistical analyses were performed using SPSS version 13.0 statistical software (SPSS, Inc., Chicago, IL, USA). P $<0.05$ was considered to indicate a statistically significant difference.

\section{Results}

Effect of BA on hemodynamics and LV function. There were no significant differences in the baseline values of the cardiovascular parameters, including LVEDP, LVDP, CF and maximum and minimum $\mathrm{LV} \mathrm{dp/dt,} \mathrm{between} \mathrm{any} \mathrm{of} \mathrm{the}$ groups. BA infusion caused virtually no changes in any of the measured cardiovascular parameters prior to ischemia in the ischemic groups. During the $30 \mathrm{~min}$ ischemia, LVDP, CF and maximum and minimum $\mathrm{LV} \mathrm{dp/dt} \mathrm{decreased} \mathrm{in} \mathrm{all} \mathrm{the}$ groups. At 60 mins of reperfusion, these parameters showed partial recoveries in the I/R groups. Recoveries of LVDP, $\mathrm{CF}$ and maximum and minimum LV dp/dt were significantly improved in groups III, IV and IV compared with those in group II, in a dose-dependent manner $(\mathrm{P}<0.05)$. LVEDP was significantly increased during the $30 \mathrm{~min}$ of ischemia, and increased again at the end of the 60-min K-H solution reperfusion period $(\mathrm{P}<0.05)$. However, the increases in LVEDP during reperfusion in groups III, IV and V were significantly smaller than those in group II, as previously reported (23).

Effect of BA on LDH and CK in coronary effluent. In all the groups, the activities of LDH and CK in the coronary effluent prior to ischemia were minimal. However, following ischemia, in group II, releases of LDH and CK into the coronary effluent were significantly increased compared with the normal group and significantly decreased in groups III, IV and V compared with group II (Table I).

Effect of BA on SOD and MDA in myocardial tissue. The level of myocardial MDA was significantly higher and SOD was significantly lower in the ischemia groups than those in the normal group $(\mathrm{P}<0.01)$. However, the levels were significantly improved in groups III, IV and V than those in group II, with the results showing a dose-dependent effect (Table II).

Infarct size and vessel density analysis. The infarct size was significantly increased in group II $(65.3 \pm 4.2 \%)$ compared with the control group $(10.6 \pm 3.5 ; \mathrm{P}<0.001)$. Furthermore, the infarct size was significantly decreased in groups III $(43.8 \pm 2.7)$, IV (38.7 \pm 2.3$)$ and $\mathrm{V}(35.4 \pm 3.1)$ compared with group II $(\mathrm{P}<0.05$, Fig. 1). The vessel density was significantly reduced in group II $(5.3 \pm 1.05)$ compared with the control group $(12.7 \pm 1.08$; $\mathrm{P}<0.001)$, while it was significantly increased in groups III (8.2 \pm 1.36$)$, IV $(9.6 \pm 1.24)$ and V $(10.4 \pm 1.09)$ compared with group II (P<0.05, Fig. 2)

Apoptosis detected by FCM. Following cell labeling with Annexin-V-FITC and PI, FCM analysis of the cardiomyocytes revealed that the percentage of apoptotic cells following I/R was significantly increased compared with normal cells (20.33 vs. $23 \%$ ). Following BA treatment $(20,40$ or $80 \mathrm{mg} / \mathrm{kg}$ ), the percentage of apoptotic cardiomyocytes was significantly increased $(\mathrm{P}<0.05)$ in a dose-dependent manner $(18.32,14.95$ and $10.12 \%$, respectively). 
Table II. Effect of baicalin on SOD activity and MDA content in I/R-induced myocardial tissue.

\begin{tabular}{lccccc}
\hline Parameter & Control & Group II & Group III & Group IV & Group V \\
\hline SOD (U/g) & $441.3 \pm 14.3$ & $180.6 \pm 23.7^{\mathrm{a}}$ & $246.7 \pm 19.5^{\mathrm{b}}$ & $345.4 \pm 13.4^{\mathrm{a}, \mathrm{b}, \mathrm{c}}$ & $408.0 \pm 18.6^{\mathrm{a}, \mathrm{b}, \mathrm{c}, \mathrm{d}}$ \\
MDA (mmol/g) & $61.2 \pm 5.8$ & $270.7 \pm 3.8 \mathrm{a}$ & $206.2 \pm 7.6^{\mathrm{a}, \mathrm{b}}$ & $148.4 \pm 5.1^{\mathrm{a}, \mathrm{b}, \mathrm{c}}$ & $80.7 \pm 4.1^{\mathrm{a}, \mathrm{b}, \mathrm{c}, \mathrm{d}}$ \\
\hline
\end{tabular}

Data are presented as the mean \pm standard error of the mean $(\mathrm{n}=10)$. ${ }^{\mathrm{a}} \mathrm{P}<0.05$, vs. control; ${ }^{\mathrm{b}} \mathrm{P}<0.05$, vs. group II; ${ }^{\mathrm{c}} \mathrm{P}<0.05$, vs. group III; ${ }^{\mathrm{d}} \mathrm{P}<0.05$, vs. group IV. SOD, superoxide dismutase; MDA, malondialdehyde; I/R, ischemia-reperfusion.

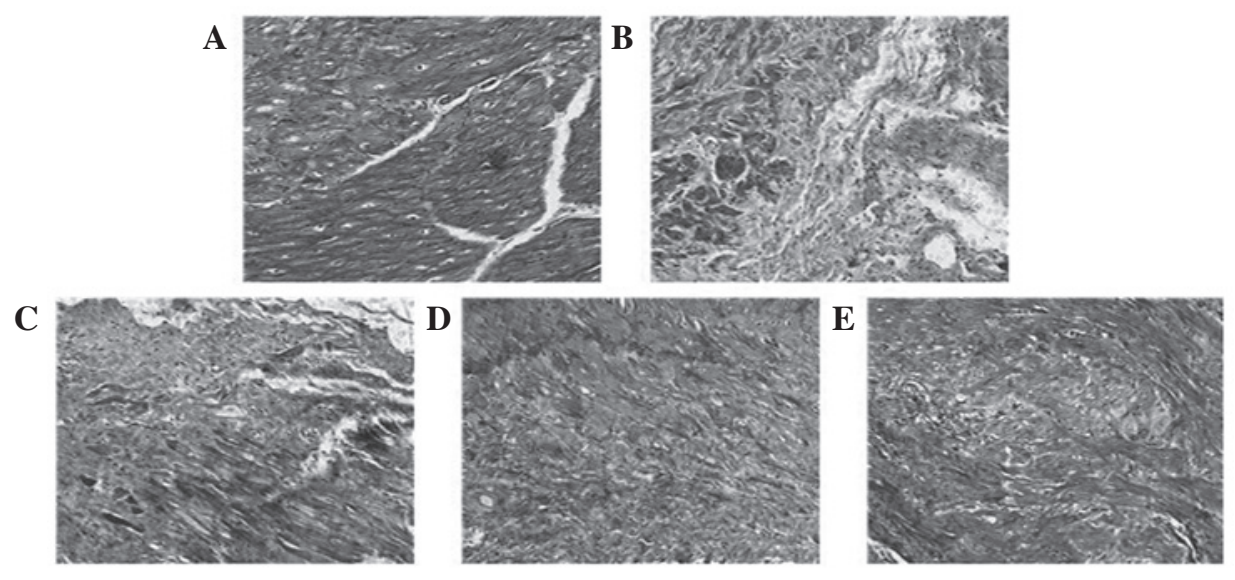

Figure 1. Effects of BA on myocardial infarct size visualized with Masson's trichrome. Compared with the (A) control group, the infarct size was significantly increased in (B) group II. By contrast, it was significantly decreased in groups (C) III, (D) IV and (E) V compared with group II (magnification, x100). Group I (control): Hearts were perfused for $90 \mathrm{~min}$ with K-H solution as a normal control for the different experimental groups. Group II (I/R): Subsequent to equilibration, hearts were subjected to ischemia for $30 \mathrm{~min}$ followed by reperfusion for $60 \mathrm{~min}$ with $\mathrm{K}-\mathrm{H}$ solution. Groups III, IV and V (I/R + BA): Hearts were perfused similarly to group II, except that the reperfusion solution contained 20, 40 and $80 \mathrm{mg} / \mathrm{kg}$ BA, respectively. BA, baicalin; K-H, Krebs-Henseleit; $\mathrm{I} / \mathrm{R}$, ischemia-reperfusion.

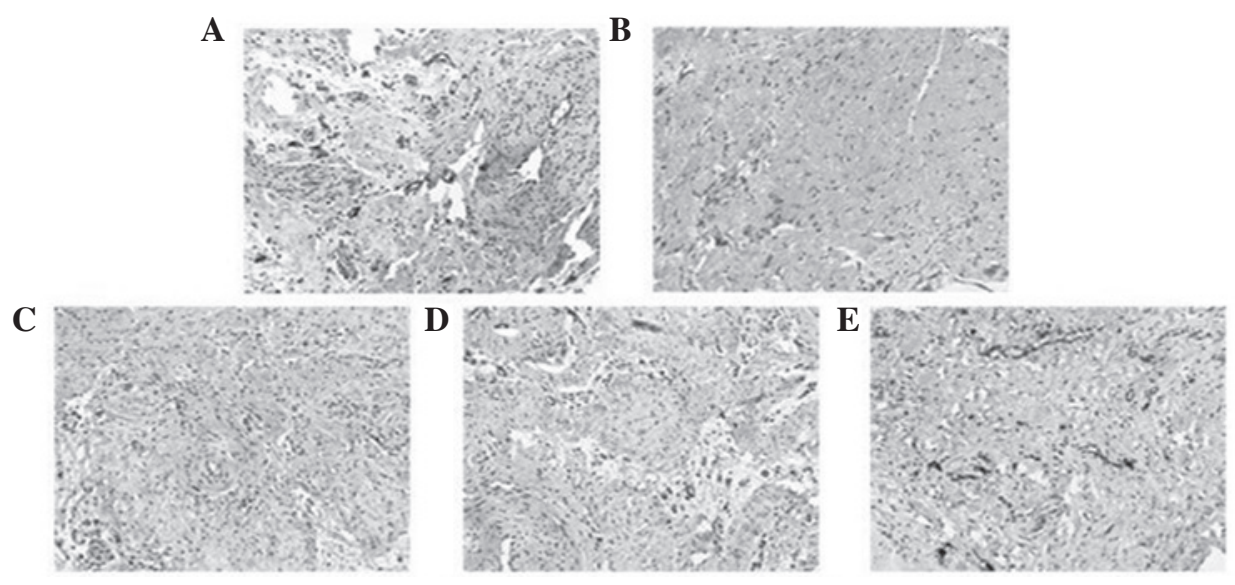

Figure 2. Effects of BA on vessel density. Vessels were stained with von Willebrand factor. Compared with the (A) control group, the density of the vessels was significantly reduced in (B) group II. By contrast, the density was significantly increased in groups (C) III, (D) IV and (E) V compared with group II (magnification, x100). Group II (I/R): Subsequent to equilibration, hearts were subjected to ischemia for 30 min followed by reperfusion for $60 \mathrm{~min}$ with K-H solution. Groups III, IV and V (I/R + BA): Hearts were perfused similarly to group II, except that the reperfusion solution contained 20,40 and $80 \mathrm{mg} / \mathrm{kg} \mathrm{BA}$, respectively. BA, baicalin; K-H, Krebs-Henseleit; I/R, ischemia-reperfusion.

\section{Discussion}

Scutellaria baicalensis Georgi is a widely used herb in traditional medical systems of China and Japan (24). Flavonoids, including baicalein, BA, wogonin and skullcap flavones I and II, are major components of Scutellaria baicalensis Georgi and have been suggested to exert antioxidant and other pharmacological effects. The variety of interesting effects exhibited by BA has led to it attracting considerable attention and it has been widely used in oriental medicine. Studies have previously demonstrated the protective effects exerted by BA in myocardial ischemia in the isolated rat heart and against 
hypoxia/reoxygenation damage in rat cardiomyocytes (12-16). The mechanisms behind this protection may be due to the antioxidant, prooxidant and anti-inflammatory effects of BA, induced by the hypoxia/reoxygenation injury to cardiomyocytes. However, the mechanisms are still not fully understood and, therefore, further studies into the mechanisms of protection are required.

I/R injury remains the leading cause of morbidity and mortality in all developed countries and is a large economic burden on the treatment and care of patients. Following cell $\mathrm{I} / \mathrm{R}$, apoptosis is one of the major pathways leading to cell death $(25,26)$. Programmed cell death, in the form of apoptosis, necrosis and, possibly, autophagic cell death are the final arbiters of cardiomyocyte numbers following myocardial infarction (27-29). Apoptosis has been ascribed a pathogenic role in $\mathrm{I} / \mathrm{R}$, particularly in the heart and brain $(30,31)$. It has been indicated that cell apoptosis is associated with a variety of damaging stimuli, particularly continuous I/R. Therefore, the inhibition of cardiomyocyte apoptosis induced by myocardial $\mathrm{I} / \mathrm{R}$ injury in the heart is particularly important for reducing myocardial damage.

In the present study, an isolated Langendorff-perfused rat heart model was used to evaluate the protective effect of BA against I/R injury. The heart was exposed to ischemia for $30 \mathrm{~min}$ and then reperfused with $\mathrm{K}-\mathrm{H}$ perfusion solution for $60 \mathrm{~min}$ to establish an I/R model in vitro. It has previously been shown that BA is able to reduce LDH leakage and increase the survival rate of cardiomyocytes undergoing I/R (7). In our experiment, the activities of LDH and CK in the coronary effluent in the I/R group were significantly increased compared with those in the normal group. Furthermore, LDH and $\mathrm{CK}$ activities were significantly decreased in the BA groups, compared with group II, in a dose-dependent manner $(\mathrm{P}<0.05)$. By contrast, the myocardial MDA and SOD levels in the BA groups were significantly lower than those in group II $(\mathrm{P}<0.05)$. Our results indicated that the protective effects of BA against I/R injury were mediated by its antioxidant activity.

As mentioned previously, studies have demonstrated that BA is able to suppress the proliferation of vascular smooth muscle cells and exert cardioprotective effects against hypoxia/reoxygenation injury. However, the mechanisms are complicated, and, to date, there has been no clear histological and immunohistochemical evidence showing the cardioprotective effects of BA. To further study the protective effect of BA, the efficacy of BA was evaluated in isolated rat hearts using histology and immunohistochemistry and cardiomyocyte apoptosis was measured using FCM. The results showed that infarct size was reduced and vessel density was augmented in the BA groups $(\mathrm{P}<0.01)$. Labeling the cardiomyocytes with Annexin-V-FITC and PI showed that the percentage of apoptotic cells in $\mathrm{I} / \mathrm{R}$ injury was significantly increased compared with normal cells $(\mathrm{P}<0.05)$. Following BA treatment $(20,40$ and $80 \mathrm{mg} / \mathrm{kg}$ ), the percentage of apoptotic cardiomyocytes was significantly increased $(\mathrm{P}<0.05)$ in a dose-dependent manner.

In conclusion, our data suggest a dose-dependent protective effect of BA against I/R injury in isolated rat hearts and indicate that the mechanisms of the protective effect may be associated with antioxidant and anti-apoptotic properties. To the best of our knowledge, this study is the first evaluation of the efficacy of BA in isolated rat hearts using histology and immunohistochemistry and may provide a theoretical foundation for the clinical treatment of AMI. Further studies in this field are must be performed.

\section{Acknowledgements}

The authors thank The Second Hospital of Shandong University and the Beijing University of Aeronautics and Astronautics for their generous support.

\section{References}

1. Garg HK and Bryan NS: Dietary sources of nitrite as a modulator of ischemia/reperfusion injury. Kidney Int 75: 1140-1144, 2009.

2. Xiao CY, Yuhki K, Hara A, et al: Prostaglandin E2 protects the heart from ischemia-reperfusion injury via its receptor subtype EP4. Circulation 109: 2462-2468, 2004.

3. Zhang WH, Fu SB, Lu FH, et al: Involvement of calcium-sensing receptor in ischemia/reperfusion-induced apoptosis in rat cardiomyocytes. Biochem Biophys Res Commun 347: 872-881, 2006.

4. Wang YL, Wang CY, Zhang BJ and Zhang ZZ: Shenfu injection suppresses apoptosis by regulation of $\mathrm{Bcl}-2$ and caspase- 3 during hypoxia/reoxygenation in neonatal rat cardiomyocytes in vitro. Mol Biol Rep 36: 365-370, 2009.

5. Eefting F, Rensing B, Wigman J, Pannekoek WJ, Liu WM, Cramer MJ, Lips DJ and Doevendans PA: Role of apoptosis in reperfusion injury. Cardiovasc Res 61: 414-426, 2004.

6. Dumont EA, Hofstra L, van Heerde WL, et al: Cardiomyocyte death induced by myocardial ischemia and reperfusion: measurement with recombinant human annexin-V in a mouse model. Circulation 102: 1564-1568, 2000

7. Borutaite V, Jekabsone A, Morkuniene R and Brown GC: Inhibition of mitochondrial permeability transition prevents mitochondrial dysfunction, cytochrome c release and apoptosis induced by heart ischemia. J Mol Cell Cardiol 35: 357-366, 2003.

8. Gao Z, Huang K, Yang X and Xu H: Free radical scavenging and antioxidant activities of flavonoids extracted from the radix of Scutellaria baicalensis Georgi. Biochim Biophys Acta 1472: 643-650, 1999.

9. Dethlefsen SM, Sherpo D and D'Amore P: Arachindonic acid metabolites in bFGF-, PDGF-, and serum-stimulated vascular cell growth. Exp Cell Res 212: 262-273, 1994.

10. Li BQ, Fu T, Dongyan Y, Mikovits JA, Ruscetti FW and Wang JM: Flavonoid baicalin inhibits HIV-1 infection at the level of viral entry. Biochem Biophys Res Commun 276: 534-538, 2000.

11. Chou TC, Chang LP, Li CY, Wong CS and Yang SP: The antiinflammatory and analgesic effects of baicalin in carrageenan-evoked thermal hyperalgesia. Anesth Analg 97: 1724-1729, 2003.

12. Lin CC and Shieh DE: The anti-inflammatory activity of Scutellaria rivularis extracts and its active components, baicalin, baicalein and wogonin. Am J Chin Med 24: 31-36, 1996.

13. Kubo M,Matsuda H, Tanaka M, Kimura Y, Okuda H, Higashino M, Tani T, Namba K and Arichi S: Studies on Scutellariae radix. VII. Anti-arthritic and anti-inflammatory actions of methanolic extract and flavonoid components from Scutellariae radix. Chem Pharm Bull (Tokyo) 32: 2724-2729, 1984.

14. Xiping Z, Hua T, Hanqing C, Li C, Zhiwei W, Keyi W, Wei Y, Yun L, Qingyu L, Qing H and Fei W: The protecting effects and mechanisms of Baicalin and Octreotide on heart injury in rats with SAP. Mediators Inflamm 2007: 19469, 2007.

15. Woo AY, Cheng $\mathrm{CH}$ and Waye MM: Baicalein protects rat cardiomyocytes from hypoxia/reoxygenation damage via a prooxidant mechanism. Cardiovasc Res 65: 244-253, 2005.

16. Lin L, Wu XD, Davey AK and Wang J: The anti-inflammatory effect of baicalin on hypoxia/reoxygenation and TNF-alpha induced injury in cultural rat cardiomyocytes. Phytother Res 24: 429-437, 2010.

17. Reichelt ME, Willems L, Hack BA, Peart JN and Headrick JP: Cardiac and coronary function in the Langendorff-perfused mouse heart model. Exp Physiol 94: 54-70, 2009.

18. Yamashiro S, Kuniyoshi Y, Arakaki K, Uezu T, Miyagi K and Koja K: Cardioprotective effects of tetrahydrobiopterin in cold heart preservation after cardiac arrest. Ann Thorac Cardiovasc Surg 12: 95-104,2006. 
19. Yamashiro S, Noguchi K, Matsuzaki T, Miyagi K, Nakasone J, Sakanashi M, Koja K and Sakanashi M: Beneficial effect of tetrahydrobiopterin on ischemia-reperfusion injury in isolated perfused rat hearts. J Thorac Cardiovasc Surg 124: 775-784, 2002.

20. Luan Y, Liu XC, Zhang GW, Shi RF, Zhao XB, Zhao CH, Liu TJ, Lü F, Yang Q and He GW: Mid-term effect of stem cells combined with transmyocardial degradable stent on swine model of acute myocardial infarction. Coron Artery Dis 21: 233-243, 2010.

21. Wang Y, Liu XC, Zhang GW, et al: A new transmyocardial degradable stent combined with growth factor, heparin, and stem cells in acute myocardial infarction. Cardiovasc Res 84: 461-469, 2009.

22. Slama P, Sladek Z, Rysanek D and Langrova T: Effect of Staphylococcus aureus and Streptococcus uberis on apoptosis of bovine mammary gland lymphocytes. Res Vet Sci 87: 233-238, 2009.

23. Ouyang HC, Wu JL and Chen JH: Protective effect of baicalin aganist myocardial ischemia and reperfusion injury in rats. Chin J New Drugs Clin Rem 256: 408-412, 2006 (In Chinese).

24. Shao ZH, Vanden Hoek TL, Qin Y, Becker LB, Schumacker PT, Li CQ, Dey L, Barth E, Halpern H, Rosen GM and Yuan CS: Baicalein attenuates oxidant stress in cardiomyocytes. Am J Physiol Heart Circ Physiol 282: H999-H1006, 2002.
25. Zhang Z, Yu B and Tao GZ: Apelin protects against cardiomyocyte apoptosis induced by glucose deprivation. Chin Med J (Engl) 122: 2360-2365, 2009.

26. Mani K: Programmed cell death in cardiac myocytes: strategies to maximize post-ischemic salvage. Heart Fail Rev 13: 193-209, 2008.

27. Kang PM and Izumo S: Apoptosis in heart: basic mechanism and implications in cardiovascular diseases. Trends Mol Med 9: 177-182, 2003

28. Saraste A, Voipio-Pulkki LM, Parvinen M and Pulkki K: Apoptosis in the heart. N Engl J Med 336: 1025-1026. 1997.

29. Kim NH and Kang PM. Kang: Apoptosis in cardiovascular diseases: mechanism and clinical implications. Korean Circ J 40: 299-305, 2010

30. Umansky SR, Shapiro JP, Cuenco GM, Foehr MW, Bathurst IC and Tomei LD: Prevention of rat neonatal cardiomyocyte apoptosis induced by simulated in vitro ischemia and reperfusion. Cell Death Differ 4: 608-616, 1997.

31. Hofstra L, Liem IH, Dumont EA, Boersma HH, van Heerde WL, Doevendans PA, De Muinck E, Wellens HJ, Kemerink GJ, Reutelingsperger CP and Heidendal GA: Visualisation of cell death in vivo in patients with acute myocardial infarction. Lancet 356: 209-212, 2000 . 